\title{
Experimental study on the use of positive pressure ventilation for fire service interventions in buildings with staircases
}

\author{
K. Lambert ${ }^{1}$ and B. Merci ${ }^{2}$ \\ ${ }^{1}$ Brussels Fire Department (Belgium) \\ ${ }^{2}$ Ghent University - UGent, Department of Flow, Heat and Combustion Mechanics, Ghent \\ (Belgium)
}

\begin{abstract}
During fire service interventions, positive pressure ventilation (PPV) systems with mobile fans are often used to try and make (or keep) a staircase smoke free and to remove smoke from the fire rooms. The positioning (distance from the door opening) and inclination angle of the fan determine the effect of the PPV fans in the staircase. In the present paper results are discussed of an experimental study, performed at full-scale. Based on different sets of cold experiments, the impact is quantified of: the distance between the fan and the door; the inclination angle of a single fan; and the use of multiple fans. The closer the single fan is put to the door opening, the more effective the PPV becomes. Obviously, there is a trade-off with effectiveness of the fire service intervention, since the fan must not block the door opening. With respect to inclination, it is best to apply an inclination angle of $75^{\circ}$ (i.e., an upward tilting of the fan axis by $15^{\circ}$, which is the maximum value tested) for ventilation at ground level with the fan tested. This ensures safety in the case of fire at ground level due to full coverage of the entry door opening, while only a relatively limited loss in PPV effectiveness is observed compared to a horizontal fan (in some cases, the PPV effectiveness is even higher with inclined fan). When the fire room is at a higher floor, an inclination angle of $90^{\circ}$ (i.e. horizontal fan axis) can generate a higher average flow velocity, depending on the staircase configuration inside the building. If 2 fans are used, $V$-shape positioning is shown to be more effective than a set-up in series or in parallel. A V-shape with inner angle of $60^{\circ}$ between the fan axes is more effective than an angle of $90^{\circ}$. If 3 fans are available, still higher average flow velocities are measured. Positioning 2 fans outside in $V$-shape and 1 fan inside at the bottom of the staircase is more effective than putting the 3 fans outside, On the other hand, the latter set-up may be required for firefighting tactics.
\end{abstract}

Keywords: Positive pressure ventilation, PPV, fire service intervention, full-scale experiments 


\section{Introduction}

Since a couple of decades, many fire services dispose of positive pressure ventilation (PPV) mobile fans for use in firefighting operations (Fig. 1). The working principle is relatively simple: the PPV fans, positioned in front of the door of a building, generate a cone shaped air stream, creating an overpressure outside the door opening. Once an exhaust opening is created (e.g. by opening one or more windows), an air/smoke stream is created along one or more pathways inside the building at hand. This technique can be used for smoke clearance after the extinguishment of the fire, but it is also possible to create ventilation during the fire service intervention, during or even before fire extinction. The latter is referred to as 'positive pressure attack' (PPA) [1].

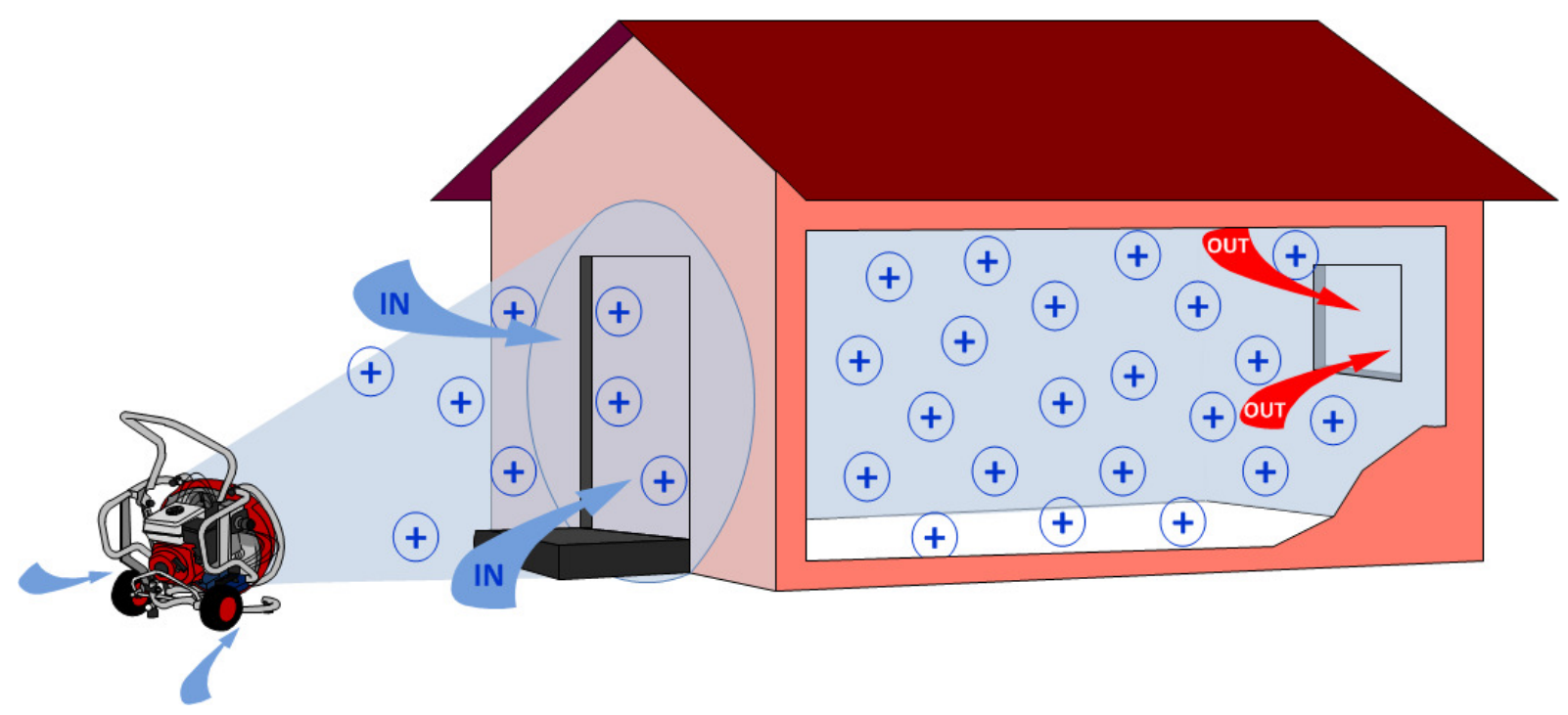

Figure 1 The principle of positive pressure ventilation.

Research has already been performed on the effectiveness of PPV. Ziesler et al [2] found that the application of PPV reduces the temperatures, reduces the toxic gas levels and improves visibility for firefighters. PPV was also reported to divert the flames into the direction away from the firefighting location, while no extra spread of heat damage was observed. The influence of PPV on the fire heat release rate (HRR) and the temperatures inside rooms with the fire has been examined by Svensson [3] and Kerber \& Walton [4]. Svensson [3] found that the rate of burning increased by the ventilation. Temperatures increased in rooms on the leeward side of the fire, and decreased in the rooms on the windward side. Kerber \& Walton [4] considered the fire room and concluded that PPV leads to slightly lower temperatures in the fire room, although the HRR increased. Ezekoye et al. [5] found that fire room venting, combined with fan application, resulted in higher temperatures than without fan application. In earlier work [6], Ezekoye et al reported experiments and simulations and concluded that enhanced mixing due to the use of PPV led to increased heat transfer to an unconscious victim, present in the room. This, however, is beyond the scope of the present paper. Indeed, the objective of the present study is not the interaction of PPV with a fire source. Rather, a comparative study is pursued in the context of keeping a staircase free of smoke, evaluating the performance of different set-ups of one or more mobile PPV fan(s). 
In this context Ezekoye et al found in another study [7] that the flow rate through an exhaust increases with increasing distance between the PPV fan and the inlet opening, up to a certain distance, beyond which the flow rate starts decreasing again. A second conclusion in [7] was that the flow rate decreases with increasing volume of the structure. A third conclusion was that an increase in exhaust area (multiple windows versus a single window) improves the PPV effectiveness. Kerber et al. [8] conclude from their study on PPV in large structures, that effective use of PPV is only applicable to a limited number of storeys. Indeed, the generated overpressure decreases with distance from the inlet opening, due to friction losses. Tuomisaari [9] performed experiments in a scale model (reduced scale 1:4). He found that PPV clearly improves the survival probability inside the compartment if the flow rate is sufficiently high. Other conclusions were that the optimal flow rate depends on the room geometry and the location of the fire, that pressurizing primarily the fire room results in vigorous turbulent flow conditions and that slight improvements of the fire room conditions were observed with a larger exhaust opening, close to the seat of the fire. In a follow-up study, Vaari and Hietamieni [10] performed experiments in a scale model (1:4) with four floors. They found that the visibility along the path of the firefighter attack was improved and gas temperatures reduced. They also found that the HRR of the fire increased by the application of PPV. They concluded that an optimum flow rate exists which sufficiently improves the conditions for the firefighting operations while the thermal load on the structures is kept to a tolerable level.

To the best of the authors' knowledge, little information is available on the PPV effectiveness when multiple PPV fans are applied. Yet, it is a common situation in practice that multiple fire engines are dispatched to a fire, so that multiple fans (one per engine) are present on the fire ground during the fire service intervention. The present study deals with the effectiveness of multiple PPV fans at one inlet opening. Experiments are discussed with 2 and 3 PPV fans so as to quantify the impact of the distance between the fans and their orientation with respect to the door opening.

Also, a PPV fan can be tilted over a certain inclination angle (relative to the horizontal plane). The effect thereof on PPV effectiveness is another interesting aspect that has not been studied extensively yet. These aspects are quantified below, based on different sets of full-scale cold experiments in two different buildings. The optimum position for a single PPV fan is looked for, in terms of effectiveness of the PPV fan. Two important factors are the distance between the fan and the door and the inclination of the fan. Note that Kerber et al. [8] also presented results for a systematic study on PPV effectiveness, but their focus was on the creation of over-pressure, with particular attention for high-rise buildings. Our study at hand focuses on the flows generated, with measurements taken in low-rise and mid-rise buildings.

The structure of the paper is as follows. First, the experimental set-up is described, including the description of the equipment and the buildings where the tests have been performed. Next, the test results are presented and interpreted. Finally, some conclusions are drawn. 


\section{Experimental set-up}

\subsection{Equipment}

\subsubsection{The PPV fans}

Three types of PPV fans have been used during the experiments. Two fans are driven by a combustion engine (ref. TGB $244 \mathrm{H6.5}$ and BD 24-H6.5 LN on [11]), while the third one has an electric engine (ref. Tempest TCA $24 \mathrm{E}$ on [11]). The propeller diameter is 610 $\mathrm{mm}$ for all fans and the maximum nominal flow rate is $8.56 \mathrm{~m}^{3} / \mathrm{s}\left(30800 \mathrm{~m}^{3} / \mathrm{h}\right)$ for the combustion engine driven fans and $8.33 \mathrm{~m}^{3} / \mathrm{s}\left(30000 \mathrm{~m}^{3} / \mathrm{h}\right)$ for the electric engine driven fan (according to AMCA standards). All technical details are found on [11]. Fig. 2 shows the fan with the combustion engine.
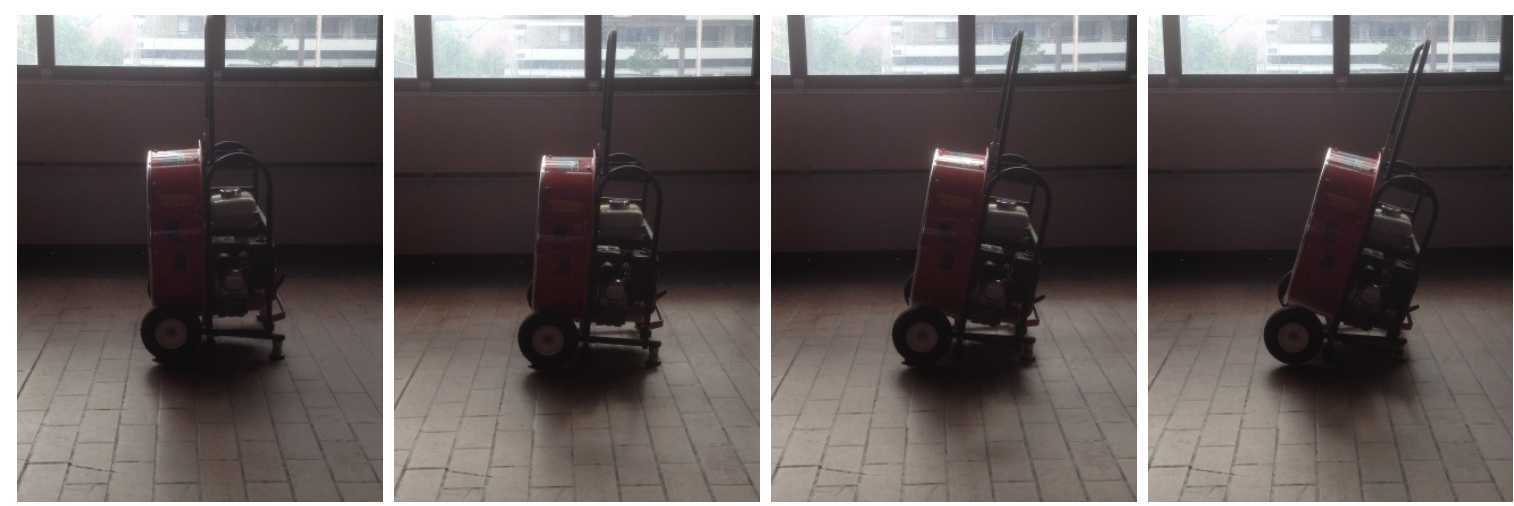

Figure 2 Inclination of the fan. From left to right: no inclination ( $90^{\circ}$, 'pos $\left.2^{\prime}\right)$, inclination angle $85^{\circ}$ ('pos $3^{\prime}$ ), inclination angle $80^{\circ}$ ('pos 4'), and inclination angle $75^{\circ}$ ('pos 5').

The PPV fans can be inclined. Five different positions can be chosen: $95^{\circ}$ ('pos $1^{\prime}$, not shown in Fig. 2 since this position is not used in the present study), $90^{\circ}$ (i.e. horizontal, 'pos $\left.2^{\prime}\right)$ ), $85^{\circ}$ ('pos $3^{\prime}$ ), $80^{\circ}$ ('pos $4^{\prime}$ ) or $75^{\circ}$ ('pos $5^{\prime}$ ). Position 5 , i.e. maximum inclination angle of $15^{\circ}$ upward from the horizontal plane, is often used by the fire service during intervention, because the generated cone of air seals the entire door opening (see also section 3.1.2). One aspect of the paper at hand concerns the comparison of results with horizontal air stream ('pos 2 ') to results obtained with 'pos 5'.

\subsubsection{Measuring equipment}

The effectiveness of the PPV fan is evaluated through velocity measurements. To that purpose, a handheld anemometer is used (the EA-3010 anemometer by Lacrosse Technology [12]). The measuring range is between $0.2-30 \mathrm{~m} / \mathrm{s}$, the accuracy is $5 \%$ and the resolution of the displayed values is $0.1 \mathrm{~m} / \mathrm{s}$.

\subsection{Measuring method}

As mentioned, the effectiveness of the PPV fan is quantified through velocity measurements. More precisely, a characteristic velocity is determined for the flow from the staircase into an apartment through the door opening. Since measurements have been taken at several floors, the door was chosen as location for the measurements, allowing faster relocation than if an exhaust opening (a door or window) had been used. 
Using the same systematic measuring methodology for all set-ups, results can be compared. It is recalled that the study is indeed comparative in nature.

Figure 3 (left) reveals how the width and height of the door opening have been divided into 3 and 5 parts, respectively. A measuring rod has been used to construct the measurement point matrix (Figure 3, right). At each of the line crossings in Figure 3, i.e. at 15 points in the door opening, measurements have been made over a period of $60 \mathrm{~s}$. The maximum value observed during this period has been taken as the characteristic velocity in that measurement point. This made the measurements feasible, taking into account that the anemometer was not equipped with a data logging system. The flow rate through the door has eventually been characterized by a single velocity value, calculated as the mean value of the maximum values at the 15 measurement points. The comparison study is based on this characteristic value. It should be noted that this approach does not take into account the fact that the major flow losses are close to the sides of the opening. However, this is not considered a problem, since a comparative study is performed: several set-ups are compared and no conclusions are drawn on absolute velocities.

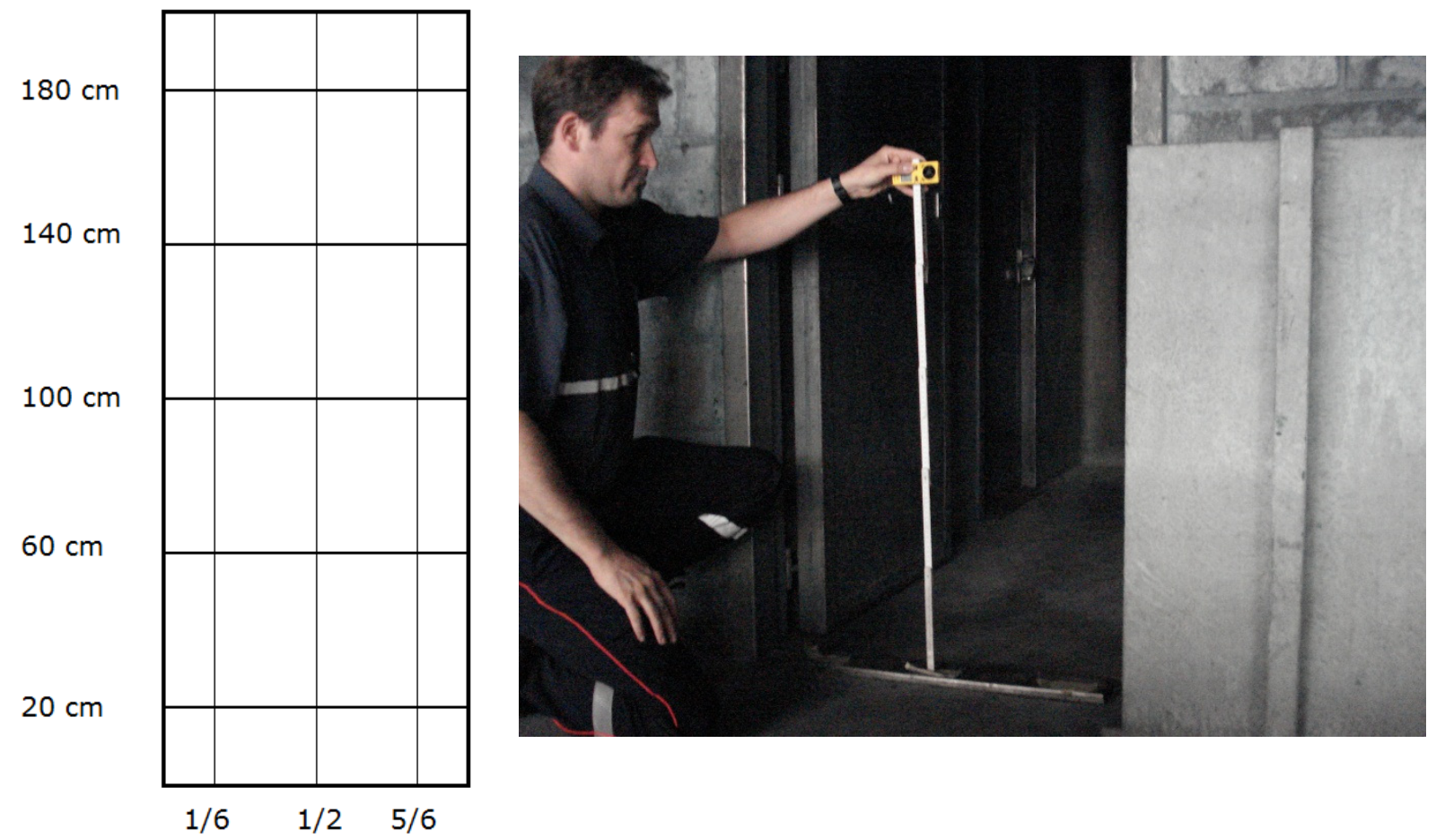

Figure 3 Left: Matrix of 15 measurement points (one measurement point per line crossing) in the door opening. Right: illustration of measurement action.

\subsection{Accuracy considerations}

The accuracy of the experiments is limited due to the measuring method used. The person holding the anemometer (Figure 3, right) and the measuring rod affect the measurement data. Yet, this does not jeopardize the main objective of the study, namely the comparison of different PPV set-ups in terms of PPV effectiveness and the according advice for fire service interventions. 
Indeed, on the one hand the comparative study does not suffer from possible deviations in absolute values, as long as the deviations are all in the same sense, compared to the 'true' value. This is the case for the factors just mentioned. Secondly, and perhaps even more importantly, the study is not intended to be an in-depth scientific study in the sense of very accurate velocity (or flow) measurements. Rather, it is intended to serve fire service interventions, where the fans will not be positioned in a very accurate manner during firefighting (from a scientific research point of view). As such, the effect of the deviation between the actual position of the fan(s) and the exact position of the fan(s) in the paper at hand, can be larger than the effect of an error caused by the measuring method. Therefore, we consider the measuring method acceptable for the sake of our study.

Another factor of uncertainty concerns wind. If the wind is directed inward towards the exhaust opening, the pressure difference between the inside and the outside will decrease, and may disappear or even reverse. Obviously, this affects the effectiveness of the PPV fans. In our experimental campaign, an experiment with one specific fan position was repeated on different days, in order to evaluate the influence of the wind. The deviations between results obtained on two days without wind, were as small as $2 \%$. However, compared to results on a windy day, differences up to $38 \%$ have been observed. Therefore, it makes no sense to compare absolute values obtained on different days. Only the analysis of trends in results obtained during consecutive tests on the same day is reported below.

\subsection{Full-scale test buildings}

The experiments have been performed in full-scale buildings. One experimental campaign has been completed in a low-rise building (ground floor + three floors), performing the measurements on the second floor. This building is a typical apartment block with seven apartments. The apartment on the second floor was fully furnished. Therefore, application of PPV will generate realistic results.
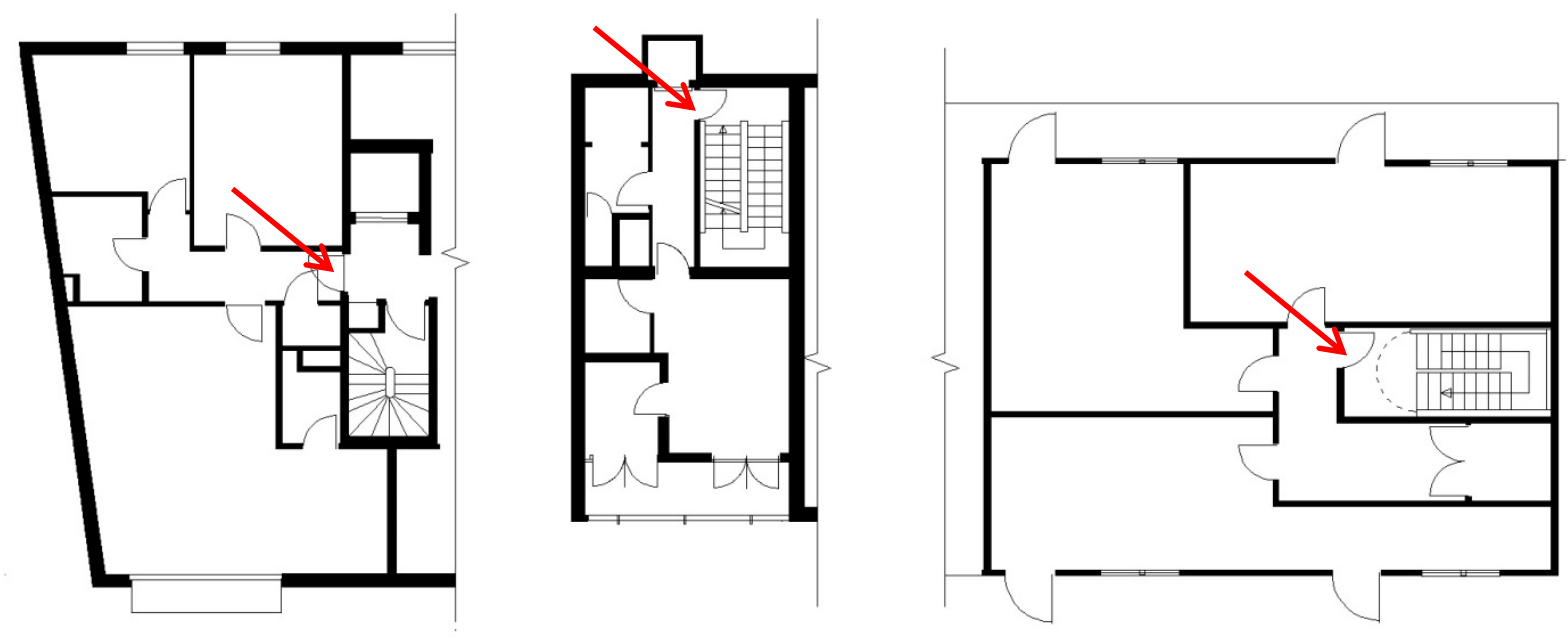

Figure 4 The layout of a characteristic floor of each of the buildings used in the experiments. Left: the second floor of the low-rise building. Middle: a characteristic floor of the exercise building of the Brussels fire department. Right: a characteristic floor of the exercise building of campus Vesta. The arrow points at the door opening, used as location for the measurements. 
Other experiments have been carried out in two mid-rise buildings: the exercise building of the Brussels Fire Department (ground floor + six floors) and the exercise building of campus Vesta, the training center for the fire service in the province of Antwerp (ground floor + five floors). Typically, such training buildings have a much larger leakage area than regular buildings. Indeed, the high amounts of heat during firefighter trainings cause deformations to doors and windows. Due to the higher leakage area, more mass of ventilation air is lost along the flow path lower air velocities are expected than in ordinary buildings. However, since this is a comparative study, this will not affect the conclusions of the study at hand.

\subsection{Experiments with 1 single fan}

The current rule of thumb in the fire service states that the fan should be placed such that the resulting air cone seals the entire door opening [13]. This is believed to be achieved when the distance between the fan and the door approximately equals the height of the door (i.e. typically at a distance of about $2 \mathrm{~m}$ from the door) and the fan is inclined over an angle of $75^{\circ}$ upward from the horizontal plane.

In order to evaluate this assumption, the PPV effectiveness of a single fan is quantified here by means of an average velocity of the flow through a door opening, as explained above (section 2.2). Several experiments have been carried out in the exercise buildings of Brussels and campus Vesta (Figure 4, middle and right). The fan is positioned outside the building at ground level. The following parameters are taken into account:

- distance between fan and entry door of the building,

- angle of inclination of the fan, and

- reduction of PPV effectiveness as the apartment considered is situated on a higher floor.

\subsection{Experiments with multiple fans}

There are several options to use multiple fans. The best known placements are "in series" ( 2 fans, one positioned behind the other) and "in parallel" ( 2 fans, one positioned beside the other). However, V-shape positioning is also mentioned in the literature [8]. In the Vshape, a virtual letter $V$ is drawn by the air flow axes through the middle of the door (as sketched in Figure 5). Thus, an angle is formed between the axes of the fans $\left(60^{\circ}\right.$ in the sketch of Figure 5). An advantage of this placement is that the fans do not hinder the firefighters entering and exiting the building. Another advantage is the possibility to put a hose in between the two fans to enter the building.

For all the experiments with multiple fans, the distance between the fans and the entry door of the building is $1.6 \mathrm{~m}$. This value has been chosen as a result of the experiments conducted with 1 single fan (see below). Still, the following parameters of the V-shaped placement have been changed:

- The inclination angle of the fans (relative to the horizontal plane), and

- The angle between the axes of the fans. 
Two test series with three fans have also been performed. The first series concerns the addition of a third fan (directed straight toward the building entry door) to the V-shape as just described. In the second series, the V-shape at the entrance of the building is combined with one additional fan inside at the entry door (from the staircase to the apartment considered).

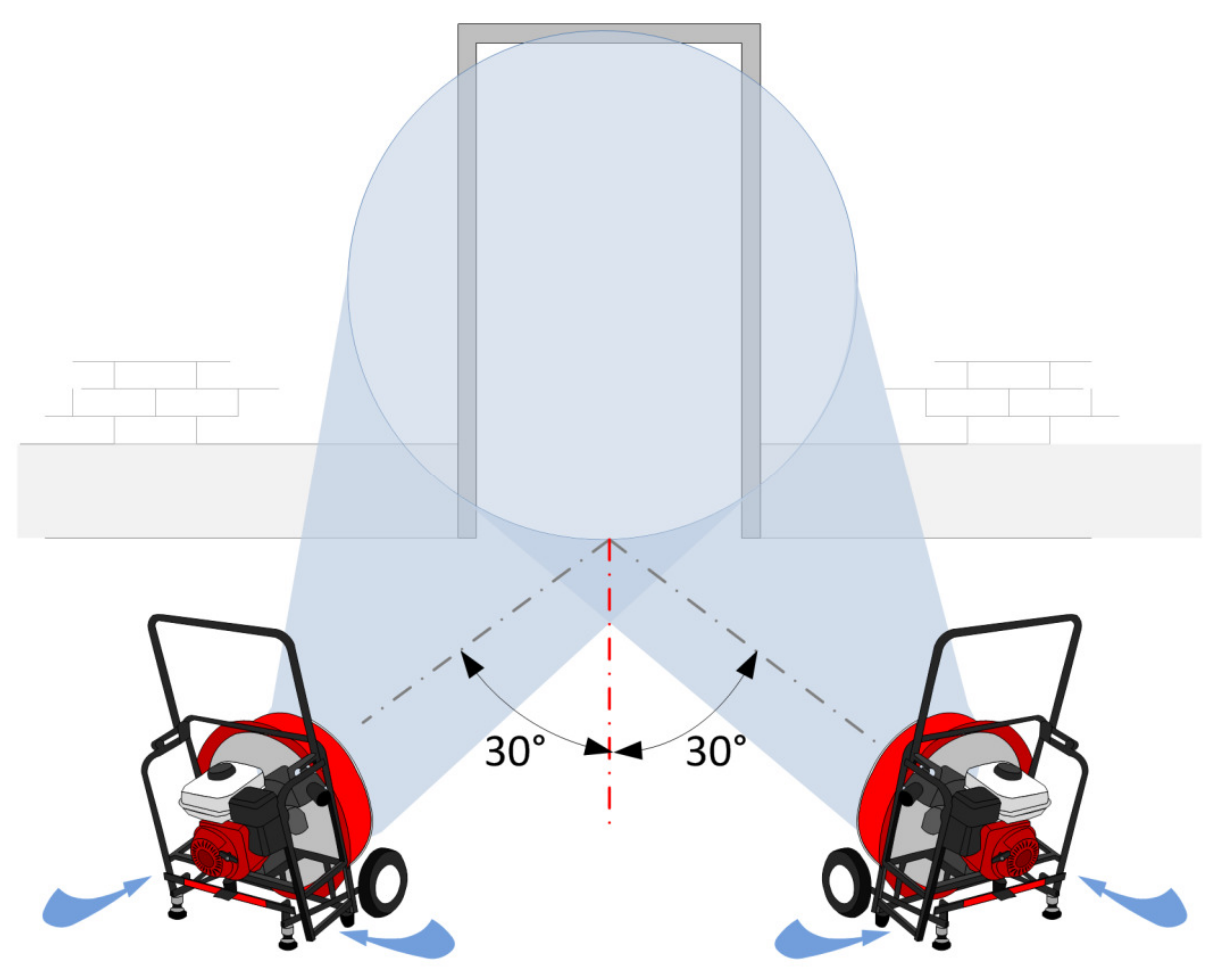

Figure 5 Placement of two fans in a V-shape. The angle between the axis of the fan and the axis of the door is $30^{\circ}$ in this picture. The angle between the axes of the fans is $60^{\circ}$.

\section{Results}

\subsection{Experiments with 1 single fan}

\subsubsection{Influence of distance between the fan and the entry door of the building}

In Figure 6 results are presented of experiments with one single fan, performed in the mid-rise exercise building of the Brussels Fire Department (Figure 4, middle). The lines correspond to results obtained with the fan driven by the electric engine, while the symbols correspond to the combustion engine driven fan (see section 2.1.1). The velocities reported have been determined as described in section 2.2. The measurements represented by the lines and the filled symbols have been taken on the second floor (red arrow in figure 4, middle), while the open symbols represent measurements at ground level. 


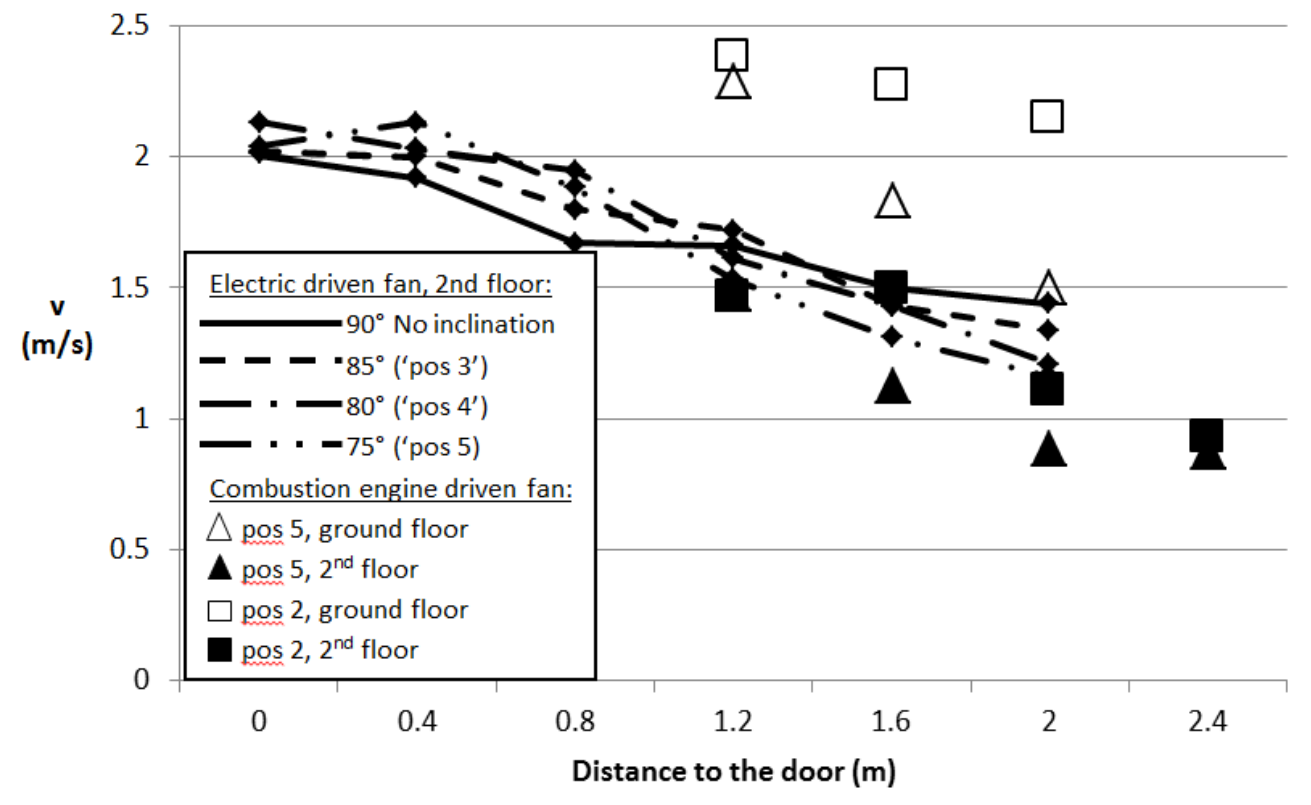

Figure 6 Impact of the distance between the fan and the entry door of the building on the effectiveness of the single PPV fan, quantified by the average flow velocity through the door, as measured in the exercise building of the Brussels Fire Department (Figure 4, middle). Lines: electric engine driven fan, measurements on the second floor, for different inclination angles; solid: $90^{\circ}$ (i.e. no inclination, 'pos 2')); dashed: $85^{\circ}$ ('pos $3^{\prime}$ ); dash-dot: $80^{\circ}$ ('pos 4'); dash-dot-dot: $75^{\circ}$ ('pos 5'). Symbols: combustion engine driven fan: 'pos 2' (squares) and 'pos 5' (triangles); open symbols: measurements at ground level; filled symbols: measurements on the second floor. Note that measurements have only been made where a symbol is depicted in the figure. The lines, connecting the symbols, have been added for clarity.

The measurements on the second floor are discussed first. Clearly, the effectiveness of the PPV fan, quantified by the characteristic velocity through the door opening on the second floor (see section 2.2), improves as the fan is positioned closer to the door, regardless whether or not the fan is inclined. This is the primary conclusion. The effectiveness is affected more strongly as the inclination angle of the fan is larger. Indeed, the slope is the largest for the 'pos $5^{\prime}$ fan (inclination angle $75^{\circ}$ ), while the weakest slope is observed for the non-inclined fan ('pos $2^{\prime}$ ). This is a second conclusion. Moreover, the curves cross. This leads to a third important observation: for larger distances, typically used in fire service interventions, the horizontal position is more effective than the inclined positions; only for short distances, it is advantageous to apply inclination to the fan. In section 3.1.2, we come back to this point, though.

With respect to fire service intervention, perhaps the most important conclusion from Figure 6 is that the 'rule of thumb' distance of 2 meter is not the optimum position for the fan. Indeed, with respect to the effectiveness of the PPV fan, the closer the fan is positioned to the door, the better. This statement is consistent with the results obtained by Lougheed, McBride \& Carpenter [14]. Putting the fan too close to the door is, however, a tactical problem for the fire service, as it impedes easy access for the firefighters on scene. A related practical problem is that the fan will be touched by water hoses while firefighters are entering the building. If, consequently, the air flow is no longer aimed at the door, the PPV fan effectiveness drops. The optimum distance from the door for fire fighter intervention will therefore be a compromise between PPV fan 
effectiveness (Figure 6) and tactical considerations. A distance of about $1.6 \mathrm{~m}$ seems a good compromise.

The filled symbols in Figure 6 give an impression of the repeatability of the experiments. They correspond to results with a combustion engine driven fan in the same building. The trends are clearly confirmed.

The open symbols show measurements at ground level. In line with the observations in [8] the PPV is more effective at ground level than on the second floor: higher velocities are measured at ground level. Overall the same trends are observed with respect to the influence of the distance between the fan and the door opening.

\subsubsection{Inclination or not}

In the previous section (3.1.1), it was concluded from Figure 6 that for large enough distance between the fan and the entry door of the building, the non-inclined position of the PPV fan is more effective. Taking into account that $1.6 \mathrm{~m}$ seems a reasonable compromise distance (see section 3.1.1), the conclusion can therefore be that no inclination be applied. However, it is essential to consider the goal of the ventilation when deciding whether the fan should be inclined or not. A distinction must be made between the situation where the fire is at ground level or not. Indeed, if the fan is not inclined and so close to the entry door that the air flow (Fig. 1) does not cover the entire door opening, a two-way current will establish in the opening. Through the lower part of the opening, air flows in, while an outward flow occurs through the upper part of the opening. With a fire at ground level, smoke will flow out with this current. In the case of a fierce fire, the accumulated smoke can be very hot and flames can occur in the upper part of the opening, endangering or making impossible the firefighters' entry in the building. Applying inclination to the fan such that an air seal is generated, i.e. overpressure is generated over the entire door opening, the flow is inward through the entire section of the door opening and the dangerous situation of exiting smoke or flames is avoided. In other words, the decision of whether or not to incline a fan in case of fire at ground level, must not solely be based on PPV fan effectiveness considerations, but also on tactical grounds. For fire at higher floors, the possible two-way current through the entry door does not pose any tactical problems and the decision on inclination or not is to be made on the basis of Figure 6.

Finally, it is important to note that the building itself also affects the impact of the inclination angle on the effectiveness of the PPV fan. The experiments in Vesta (Figure 4, right), summarized in Figure 7 , show that the inclined fan $\left(75^{\circ}\right)$ has a $19 \%$ higher effectiveness than the non-inclined fan at the second floor, contrary to what was observed in Figure 6. An important difference between the building in Brussels and the building at Vesta is the position of the staircase. The air current has to make a $180^{\circ}$ turn to enter the staircase in Brussels while this is only $90^{\circ}$ at Vesta. The geometry of the building (and particularly of the staircase inside the building) clearly affects the flow. 


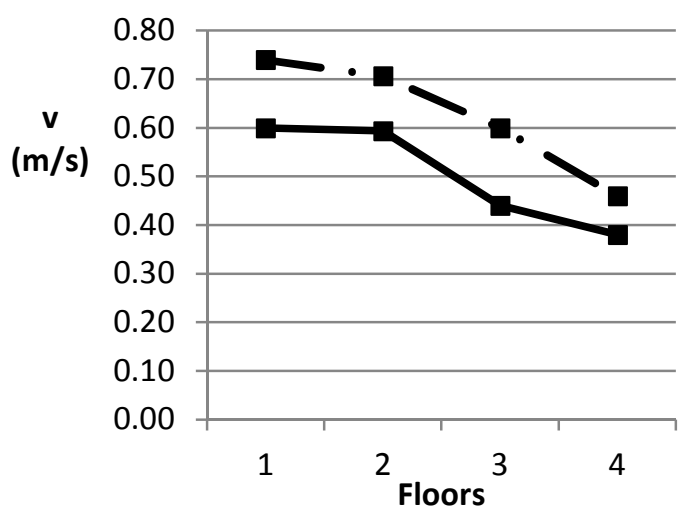

Figure 7 Reduction of average flow velocity with higher floor level (measurements taken in Vesta building, Figure 4, right). Distance between fan (combustion engine driven) and entry door of the building is equal to $1.6 \mathrm{~m}$. Line types refer to inclination angle w.r.t. the horizontal plane: solid: $90^{\circ}$ (i.e. no inclination, 'pos 2')); dash-dot-dot: $75^{\circ}$ ('pos 5'). Note that measurements have only been made where a symbol is depicted in the figure. The lines, connecting the symbols, have been added for clarity.

Summarizing, it is suggested to apply fan inclination in case of a fire at ground level, in order to obtain an air seal in the entry for the firefighters. In the case of ventilation for higher floors, the fan can be used in horizontal position since then there is no danger of hot smoke emerging, while the PPV fan effectiveness can be higher, depending on the staircase configuration inside the building.

Another logical observation from Figure 7 is that the velocities decrease at higher floor levels. This is in line with results of Kerber et al [8]. This decrease in velocity can be explained by losses through leaks in the staircase. At higher floors, the volume of the ventilated structure also increases. The decrease of velocities with increasing volume is consistent with the findings of Ezekoye et al [7].

\subsection{Experiments with multiple fans}

\subsubsection{V-shape set-up with 2 fans}

Figure 8 (top) shows the comparison of results of a single fan and three $V$-shape set-ups with 2 fans in the Vesta building (section 2.4). The angle of the $V$ (Figure 5) is $90^{\circ}(2 \mathrm{x}$ $\left.45^{\circ}\right)$. As expected, the two fans together provide substantially higher average flow velocities than the single fan. Differences between the 3 different set-ups (none inclined, both inclined or one horizontal and one inclined) are small. Thus, although the noninclined set-up systematically provides the highest average flow velocities, it is advised in the light of safety, as discussed in section 3.1.2, to incline the fans such that the entire entry door opening is entirely covered by the incoming air stream.

Figure 8 (bottom), reporting measurements at the $2^{\text {nd }}$ floor level in a low-rise building (section 2.4), essentially confirms the observations of Figure 8 (top). Slightly larger differences are observed between the $3 \mathrm{~V}$ set-ups (with again the highest average flow velocities with both fans in horizontal set-up and the lowest when one is horizontal and one at maximum inclination angle). The main observation remains that the average flow velocities are substantially higher with any of the $V$ set-ups than with the single fan. 
Figure 8 (top) also shows how the generated velocity decreases at higher floor levels. The decrease in velocity is very similar for all three $V$ set-ups. The velocities also decrease with the single fan set-up, albeit less rapidly. This is logical, since the absolute values are lower, so that the losses through the leaks in the staircase are smaller.
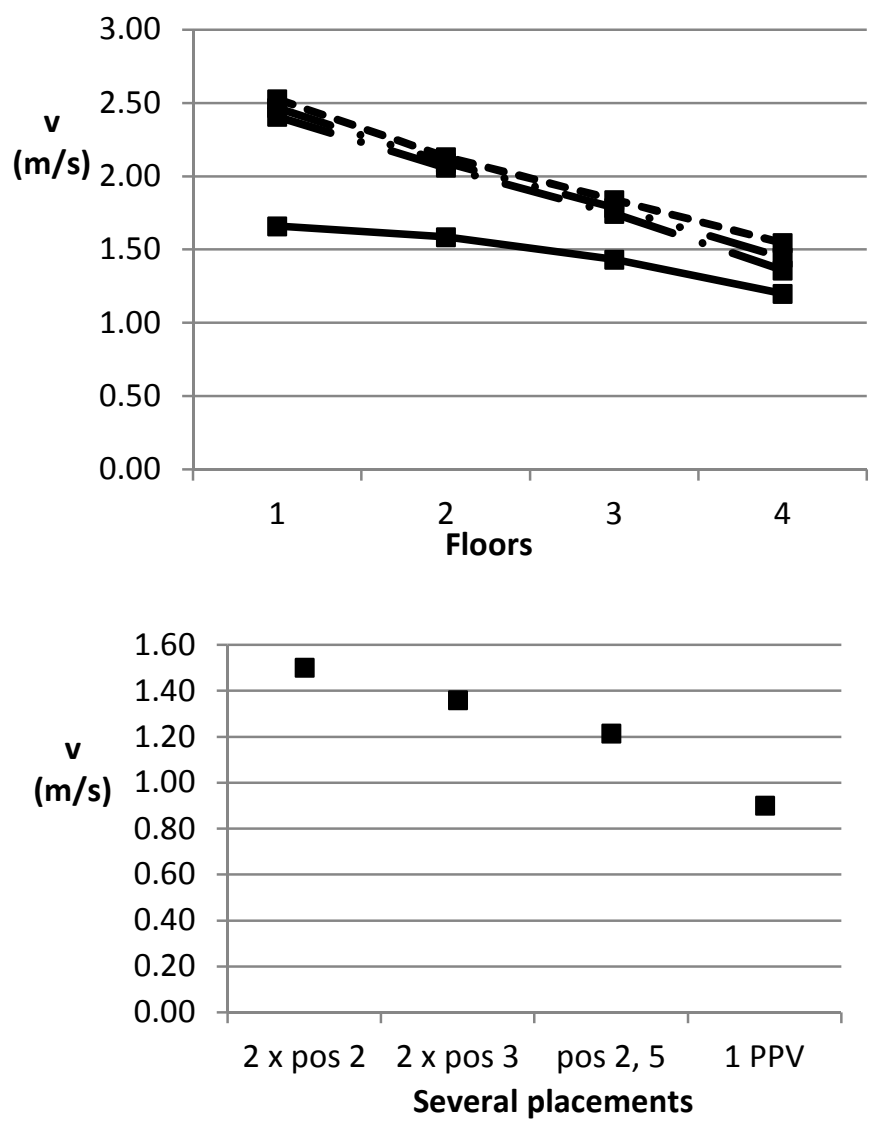

Figure 8 Top: measured velocities at Vesta building (Fig. 4, right) at 4 floor levels above ground floor. All fans are combustion engine driven. In case of 2 fans, they are in $\mathrm{V}$ setup with angle of the $\mathrm{V}$ equal to $90^{\circ}$. Line types: solid: 1 fan (inclination angle $90^{\circ}$ ); dashed: 2 fans, both horizontal ( $2 \times$ pos $\left.2^{\prime}\right)$; dash-dot: 2 fans, one horizontal, one inclined $\left(75^{\circ}\right)$ ('pos 2, pos $5^{\prime}$ ); dash-dot-dot: 2 fans, both inclined ( $\left.85^{\circ}\right)$ ('2 x pos $3^{\prime}$ ). Note that measurements have only been made where a symbol is depicted in the figure. The lines, connecting the symbols, have been added for clarity. Bottom: measured velocity at $2^{\text {nd }}$ floor level in a low-rise building (Fig. 4, left).

\subsubsection{V-shape set-up with 2 fans: influence of side walls}

Results of the test measurements in the building in Brussels (section 2.4) reveal a potentially considerable influence of the presence of side walls beside the fans. Figure 9 (left) shows results for a $V$ set-up (angle $60^{\circ}$ ) of 2 horizontal fans placed at a distance of $1.6 \mathrm{~m}$ from the entry door, with side walls at a distance of $1.6 \mathrm{~m}$ and $2 \mathrm{~m}$ from each of the fans. Figure 9 (right) shows a sketch of the set-up (top view).

Clearly, if the fan set-up is in between walls, a single fan can even generate a higher average flow velocity than 2 fans in V-shape, because the effectiveness of each of the 2 fans reduces, the flow into the back of the fans being hindered by the side walls. This is an important observation in the light of fire service intervention tactics. In fact, any 
physical object (including personnel) blocking the fan or the flow path should be avoided, since it might have a large influence on the flow. Such issues should be stressed when instructing firefighters on ventilation tactics.
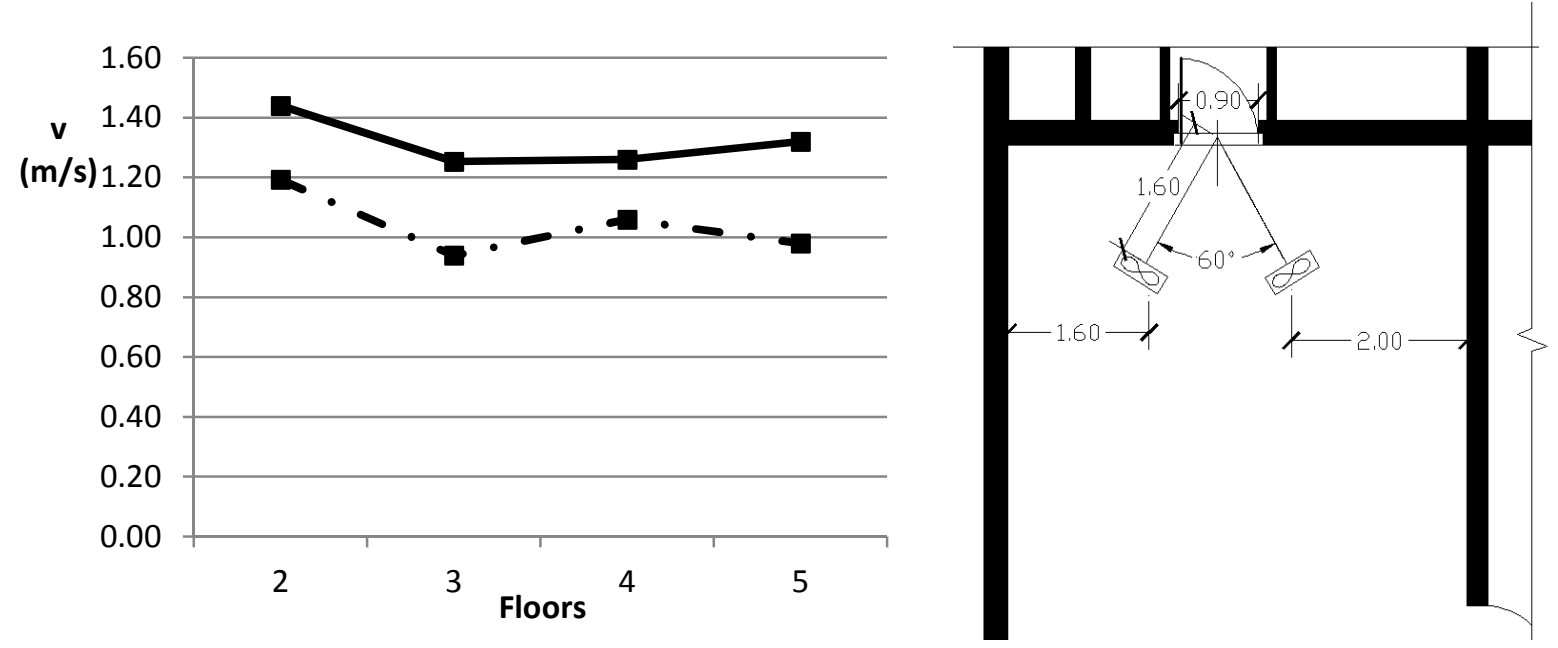

Figure 9 Left: measured velocities in the exercise building of the Brussels fire service. Solid line: 1 fan; dash-dot line: 2 fans in $V$ with a $60^{\circ}$ angle between the axes of the fans. All fans are combustion engine driven and placed in a horizontal position (inclination angle $90^{\circ}$ ). Note that measurements have only been made where a symbol is depicted in the figure. The lines, connecting the symbols, have been added for clarity. Right: top view of the fan set-up with the two fans in $V$ and the presence of two side walls (used to generate the results in the left figure).

\subsubsection{Comparison of different set-ups with 2 fans}

Figure 10 shows results with 6 different set-ups with 2 fans measured in the low-rise building (Figure 4, left). All measurements were taken on the second floor. The top figure is a sketch of the different set-ups. The result of a set up with 1 PPV in front of the door is added for comparison reasons. It is very clear that adding a second fan increases the velocity of the flow. The two V-shape set-ups are superior in terms of PPV effectiveness, with the $60^{\circ}$ angle clearly the best. This set-up does not hinder a fire service intervention, either. Therefore, it is advised to use a V-shape set-up with $60^{\circ}$ angle. 

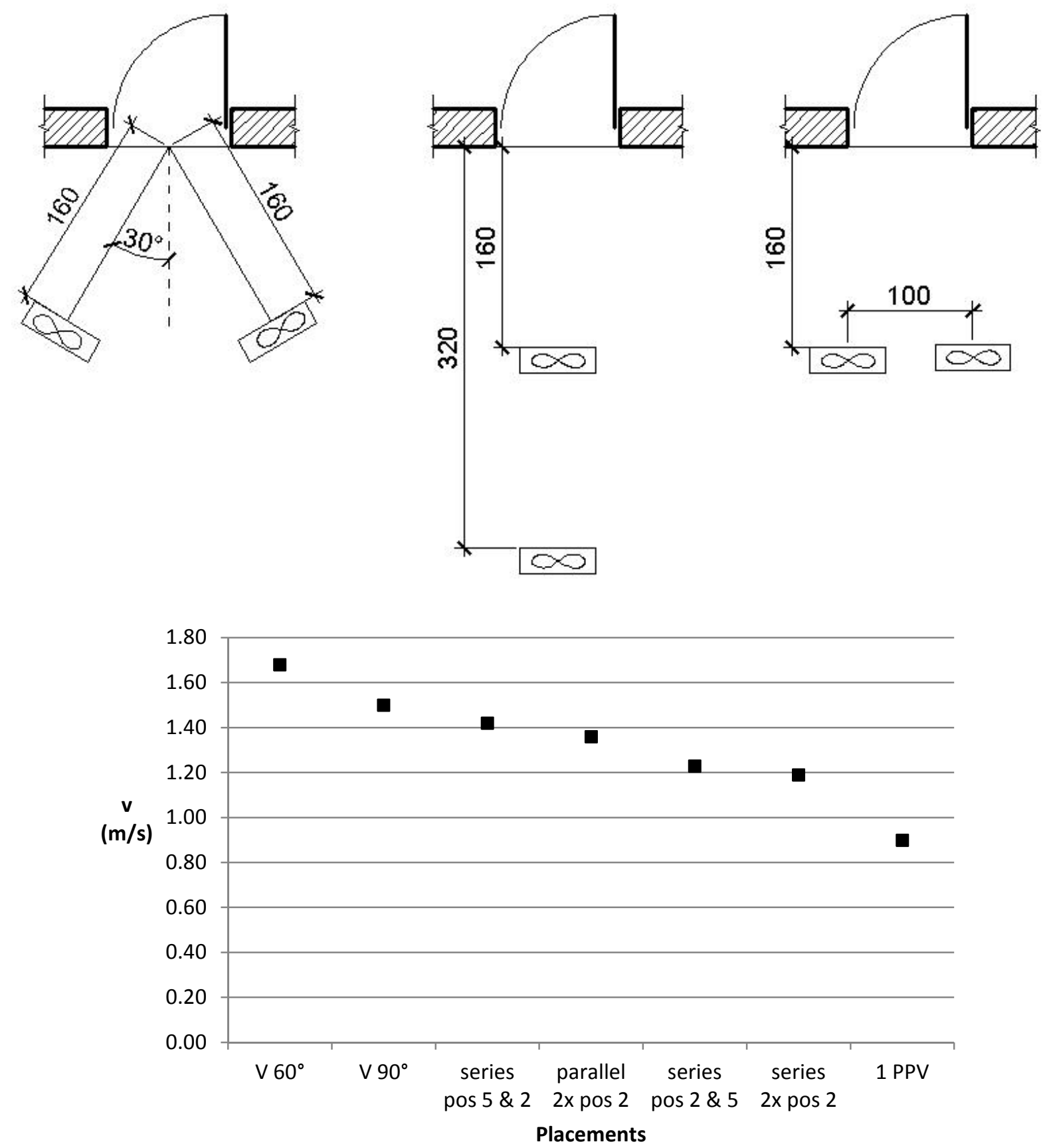

Figure 10 Top: sketch of the different set-ups. From left to right: V-shape, series, parallel. Bottom: Comparison of different set-ups with 2 fans. All measurements were taken in the low-rise building (Figure 4, left). $V 60^{\circ}$ : V-shape with an angle of $60^{\circ}$ between the fans (both horizontal); $\mathrm{V} 90^{\circ}$ : $\mathrm{V}$-shape with an angle of $90^{\circ}$ between the fans (both horizontal); series: 2 fans, one behind the other (' $2 x$ pos2': both fans horizontal; 'pos 5\&2': first fan inclined $\left(75^{\circ}\right)$, second horizontal; 'pos 2\&5': first fan horizontal, second inclined $\left(75^{\circ}\right)$ ), parallel: both fans (horizontal) next to each other (distance between fans: $0.4 \mathrm{~m}$ ). Horizontal distance from entry door of building: $1.6 \mathrm{~m}$. The result of 1 PPV fan in the low-rise building is shown to illustrate the advantages of placing two fans. 


\subsubsection{Experiments with 3 fans}

In the low-rise building (Figure 4), some experiments have also been carried out with 3 fans. Figure 11 (top) provides a sketch of the 2 set-ups tested. In the ' 3 in $V^{\prime}$ set-up, all three fans are positioned outside. In the ' 2 out +1 in' set-up, an external set-up in $\mathrm{V}$ shape is combined with a third fan inside at the entrance door into the staircase. A possible drawback of this latter set-up is that the inside fan may hinder the firefighters on scene.

Figure 11 (bottom) reveals that if 3 fans are available, the average flow velocities are higher than what can be obtained with 2 fans (and a fortiori higher than what can be obtained with 1 single fan). In terms of PPV effectiveness, it is best to put 1 fan inside. With this set-up, the two external fans feed the fan at the bottom of the staircase and the friction losses in the lobby are overcome. However, as just mentioned, the trade-off with firefighting tactics may well lead to the decision that the 3 fans are positioned outside.
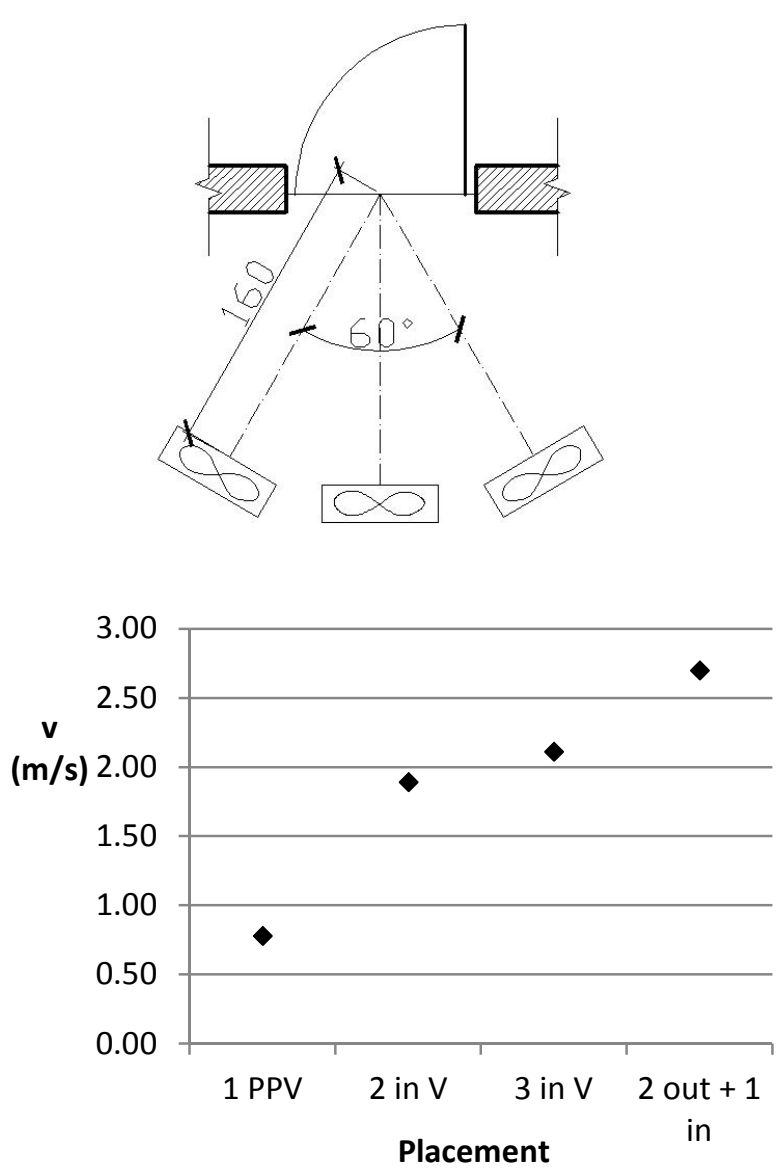

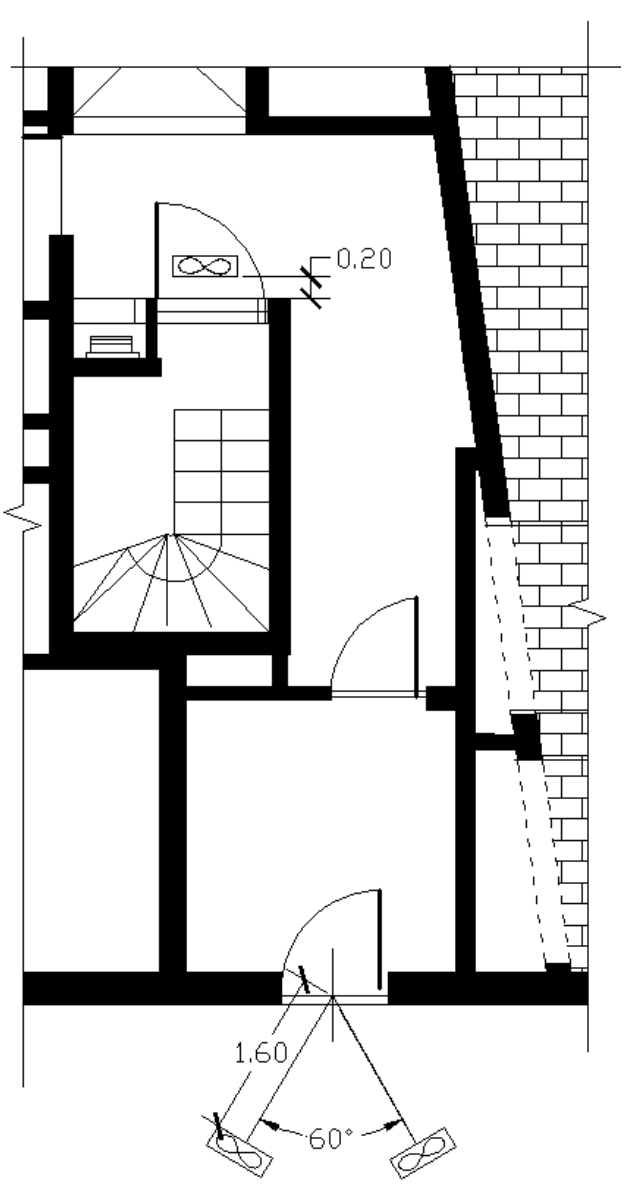

Figure 11 Bottom left: Results of 4 different placements in a low-rise building (Figure 4, left). From left to right: one fan, two fans in a V-shape, three fans in a V-shape (one extra fan in the middle) and two fans in a V-shape outside + one fan at the bottom of the stairs. All fans positioned horizontally except for the fan that was put inside (which had an inclination of $75^{\circ}$ ). Top left: The ' 3 in $V^{\prime}$ set-up, placed at the entrance door of the building. Right: The ' 2 out +1 in' set-up. The middle fan of the ' 3 in $V$ ' set-up has been placed in front of the door giving access to the staircase. 


\section{Conclusions}

Results have been presented from a series of experimental campaigns, performed in different buildings and with different set-ups of mobile fans. Both single and multiple fan configurations have been discussed. It is important to note that all the experiments have been done with the same type of fan, as discussed in section 2.1.1. The conclusions below are therefore only valid for this type of fans. Other types of fans are on the market and Lebey et al [15] found that the flow rate generated by a fan at a certain distance from the inlet opening strongly depends on the design of the fan. The conclusions of this research project may not (all) be valid for other types of fans.

The main observations are the following:

The main observations in conditions where only one single fan is used, are as follows. Firstly, the PPV fan becomes more effective as it is positioned closer to the building entry door. Considering tactical firefighting implications, in that the fan must not hinder the intervention, a distance of $1.6 \mathrm{~m}$ from the exit door seems a good rule of thumb.

Second, for ventilation in case of a fire at ground level, it is best to incline the fan up to $75^{\circ}$ (i.e. an upward inclination of $15^{\circ}$ from the horizontal plane, which is the highest value tested in the present study). From a safety point of view, the ensured coverage of the entire door opening prevents hot smoke or flames emerging through the upper part of the door opening. As far as PPV fan effectiveness is concerned, a loss (compared to horizontal positioning of the fan) is observed in some buildings, but not always. The latter depends on the staircase geometry inside the building. In any case, the potential loss in PPV effectiveness does not justify taking a potential risk in putting the fan in horizontal position.

For ventilation of rooms on higher floors, the horizontal positioning of the fan $\left(90^{\circ}\right)$ can lead to higher effectiveness.

Finally, The PPV fan effectiveness reduces at higher floors, in line with previous studies such as [8].

If 2 fans are used, V-shape set-ups are superior, compared to set-ups in series or in parallel. A V-shape with inner angle of $60^{\circ}$ between the fan axes produces higher average flow velocities than an angle of $90^{\circ}$. Whether or not the fans are inclined is of secondary importance, although the highest average flow velocities are observed with both fans in horizontal position. Yet, as was the case with the single fan, the risk of hot smoke or flames emerging through the upper part of the opening must be considered as well.

The PPV effectiveness reduces at higher floors. The reduction is stronger than for a single fan, due to increased mass and load losses per floor level. Still, all average flow velocities remain substantially higher than what is obtained with a single fan.

The presence of side walls, close to the fans, can cause a dramatic reduction in PPV effectiveness. With $V$-shape set-up, even lower average flow velocities have been observed than with a single fan, pointing straight at the door opening, due to air being hindered to flow into the fans.

Set-ups have been tested with 3 fans in place. Unsurprisingly, higher average flow velocities have been obtained than with 2 fans. 
The highest PPV effectiveness has been observed with 2 fans positioned in V-shape outside and 1 fan inside at the bottom of the staircase. The 2 external fans then feed the inner fan and friction losses are overcome. However, firefighting might be hindered by the inner fan. If so, a good alternative is to put all 3 fans in V-shape outside, the middle fan pointing straight at the exit door opening.

\section{Acknowledgments}

This paper is a summary of the thesis of Karel Lambert [16], performed in the context of the Postgraduate Studies in Fire Safety Engineering at Ghent University. The first author greatly acknowledges the financial support from KCCE, the Belgian center of expertise for the fire service, the material support of the Brussels fire department and the campus VESTA. The authors also acknowledge Associate Professor Stefan Svensson (Lund University) for his valuable comments during the research. Finally, the authors thank Bart Noyens and Ruxandra Darmon for the illustrations in this paper.

\section{References}

[1] Garcia K, Kauffmann R, Schelbe R (2006) Positive pressure attack for ventilation \& firefighting. Pennwell, US

[2] Ziesler PS, Gunnerson FS, Williams SK (1994), Advances in positive pressure ventilation: Live fire tests and laboratory simulation. Fire technology, vol 30, pp 269-277

[3] Svensson S (2001) Experimental study of fire ventilation during fire fighting operations. Fire technology, vol 37, pp 69-85

[4] Kerber S, Walton W (2005) Effect of positive pressure ventilation on a room fire. NISTIR 7213, Gaithersburg, MD, USA: National Institute of Standards and Technology

[5] Ezekoye et al. (2005) Effects of PPV Attack on Thermal Conditions in a Compartment Downstream of a Fire. Fire Technology, vol 41, pp 193-208

[6] Ezekoye OA, Hal CH, Nicks R (2003) Positive pressure ventilation attack for heat transport in a house fire, in The $6^{\text {th }}$ ASME-JSME Thermal Engineering Joint Conference, March 16-20, 2003

[7] Ezekoye OA, Svensson S, Nicks R (2007) Investigating positive pressure ventilation, In Proceedings: $11^{\text {th }}$ International Fire Science \& Engineering Conference (Interflam'07), $3^{\text {rd }}-5^{\text {th }}$ September, InterScience Communications, London, 2007.

[8] Kerber S, Madrzykowski D, Stroup D (2007) Evaluating positive pressure ventilation in large structures: high-rise pressure experiments. NISTIR 7412, Gaithersburg, MD, USA National Institute of Standards and Technology

[9] Tuomisaari M (1997) Smoke ventilation in operational fire fighting. VTT publications 326, Technical research centre of Finland

[10] Vaari J, Hietaniemi J (2000) Smoke ventilation in operational fire fighting. Part 2: Multi-story buildings. VTT publications 419, Technical research centre of Finland

[11] www.tempest-edge.com

[12] www.lacrossetechnology.com

[13] Svensson S (2000) Fire Ventilation. Swedish Rescue Services Agency. Karlstad, Sweden. https://msb.se/RibData/Filer/pdf/20879.pdf 
[14] Lougheed GD, Mcbride PJ, Carpenter DW (2002) Positive pressure ventilation for high-rise buildings. National Research Council Canada

[15] Lebey, MM, Vidor R (2002) Development of a free jet generated by an axial turbine in an open space Application to Ventilation in Fire Fighting (VFF). In Proceedings: 11th International Symposium on Applications of Laser Techniques to Fluid Mechanics. Lisbon, Portugal. July 2002.

[16] Lambert K (2012) Experimentele studie van het gebruik van overdrukventilatie in een traphal bij een brandweerinterventie. (Experimental study into the usage of positive pressure ventilation in a staircase during a fire service intervention) Dissertation, Ghent University - in Dutch. 